\title{
Desigualdade e desempenho: uma introdução à sociologia da escola brasileira
}

\author{
Maria Lígia de Oliveira Barbosa \\ Belo Horizonte, MG: Argvmentvm, 2009, 272 p.
}

Maria Lígia de Oliveira Barbosa, que há algum tempo se dedica aos estudos da sociologia da educaçáo, vem somar a este campo sua contribuição, por meio do desenvolvimento de pesquisas, realizadas com o intuito de compreender a relaçáo entre desigualdade e desempenho no âmbito escolar. O livro de sua autoria Desigualdade e desempenho: uma introdução à sociologia da escola brasileira é uma prova da concentraçáo de esforços desta professora e pesquisadora que, somados à sua experiência no campo da sociologia das profissóes, revela novas possibilidades de reflexão, além de vislumbrar no plano político a possibilidade de traçar caminhos mais otimistas, ainda que o quadro estabelecido não seja animador no que concerne ao desempenho das crianças nas duas áreas clássicas da educação básica: a linguagem e a matemática.

Conjugados ao trabalho da autora, estáo os suportes teóricos utilizados e um interessante percurso investigativo que resultou num trabalho empírico de fôlego. $\mathrm{O}$ resultado se traduz em uma notável contribuição metodológica, esmiuçada a partir de análises estatísticas e de escolhas bibliográficas calcadas em referências exemplares e atualizadas. Seu livro agrega pertinente contribuição metodológica para pesquisas deste porte na sociologia produzida no Brasil. Se, em nosso país, como constata a autora, há ainda certa indigência bibliográfica 
no que diz respeito ao conhecimento dos métodos didáticos e procedimentos pedagógicos e administrativos nas escolas do país, bem como os seus efeitos em outros países - a França, em particular -, muito se tem avançado na área da educação. Desde a década de 1960, as pesquisas têm buscado demonstrar a estreita relação entre as desigualdades sociais e as diferenças de acesso e de desempenho no sistema escolar.

A pertinência do tema se justifica num momento em que a educaçáo se tornou (ainda que em diversos casos no plano retórico) um dos centros de atenção do debate político no país. A autora desenvolve a sua sociologia da escola brasileira, buscando investigar os mecanismos da desigualdade no país e tomando a instituição escolar como "fator crucial na determinação dos destinos sociais e escolares dos estudantes". Desse modo, fatores como as condiçóes socioeconômicas das famílias tema clássico e recorrente nas análises desta envergadura - deixam de ser exclusivos na compreensão deste processo.

De sua rica investigação bibliográfica a autora aponta que pesquisadores do mundo inteiro vêm desenvolvendo trabalhos em duas vertentes: no aprofundamento do conhecimento sobre o funcionamento do sistema educativo e na exploração das relaçóes entre escola e a formação de identidades coletivas (gênero, raça e classes). $\mathrm{Na}$ introduçáo, faz um breve balanço do estado da arte no campo de trabalhos sobre a desigualdade - que é bastante amplo - apontando para uma produção recente, alguns dos quais desafiadores, ousados e polêmicos, como os de Grunsky (em parceria com Soresen ou Weeden), que buscaram agregar o pensamento clássico de Durkheim ao debate atual, antes restrito às disputas entre neo-marxistas e neo-weberianos, que chamaram a atenção para a análise das desigualdades de classes, considerando as identidades ocupacionais e a diferenciação social a elas associada.

A área da educação é o locus onde o estudo das diferentes dimensões das desigualdades sociais tem avançado. Registra a autora, com razão, que possivelmente é uma das áreas que apresenta o mais diversificado panorama teórico-conceitual e de pesquisa empírica. Este avanço se processa, tanto no aspecto teórico quanto em relaçáo aos seus desdobramentos em pesquisas, náo somente nas experiências acadêmicas internacionais, mas também na produção brasileira.

Maria Lígia concentra seu trabalho de pesquisa calcado em uma base de dados construída a partir de esforços investigativos em 24 escolas públicas (municipais e estaduais) de Belo Horizonte, lançando mão de técnicas de análise, em seu dizer, "desenvolvidas mais recentemente para refinar e aprofundar a definição dos fatores escolares que influenciam diferencialmente os alunos" (p. 31). Dessa maneira, pro- 
cura examinar as escolas e os seus procedimentos administrativos e pedagógicos, ressaltando pesquisas anteriores que já haviam constatado que tais procedimentos influenciam o desempenho de diferentes grupos sociais.

A reflexão da autora sobre o sistema escolar brasileiro se processa conjugada às diferenças raciais, de gênero e de classes sociais. Seu percurso metodológico é minuciosamente desdobrado com base na utilizaçáo dos dados dos surveys conduzidos em 24 escolas de Belo Horizonte, cuja construção se encerra na possibilidade de captação de informaçóes, como as características individuais e familiares dos estudantes, os métodos pedagógicos e o funcionamento da sala de aula, as formas de organização da escola - do ponto de vista administrativo e também de suas políticas para qualificação dos professores.

A riqueza dos dados foi construída seguindo técnicas diferenciadas como questionários, entrevistas, observação de aulas e dos cadernos dos estudantes, além de testes de português e de matemática, desenvolvidos pela Organização das Nações Unidas para a Educaçáo, a Ciência e a Cultura/Oficina de Educación para America Latina y el Caribe (Unesco/Orealc) como medida de desempenho dos estudantes de uma turma de $4^{\text {a }}$ série sorteada em cada uma das escolas investigadas.

A autora busca realizar o tratamento analítico dos dados, desenvolvendo-o a partir de modelos estatísticos que permitem, dentro de suas ambiçóes, organizar o conjunto de fatores sociais e individuais que impactam o desempenho dos alunos. Por outro lado, possibilitam, também, diz a autora, "estabelecer o peso ou a importância de cada um desses fatores na explicaçáo do fenômeno" (p. 32). O recurso lançado dessa modelagem estatística não permite que a autora perca de vista a dimensão qualitativa.

No capítulo 1, o leitor encontra o detalhamento da pesquisa empírica a partir de uma descriçáo sobre os procedimentos metodológicos. Descriçáo esta que possui um caráter didático, sem necessariamente se constituir em uma "receita de bolo", mas que serve de modelo a estudantes e pesquisadores e, generosamente, a autora apresenta nos anexos os diversos questionários utilizados. Este capítulo inicial oferece um panorama fundamental para o leitor compreender todo o processo da pesquisa e a contextualizaçáo dos programas elaborados pelas políticas educacionais, nos âmbitos estadual e municipal, como o Pró-Qualidade e a Escola Plural, respectivamente. Por outro lado são apresentados aspectos gerais sobre os fatores individuais, os fatores sociofamiliares e as variáveis institucionais ou escolares.

No capítulo 2, a autora investe nos temas clássicos da sociologia da educação, discutindo as relaçóes que podem ser estabelecidas entre o desempenho escolar e a 
situação social dos alunos. Isto é, a família é abordada como fator de desempenho escolar. Resulta daí um olhar atento com base no agrupamento dos dados em torno de questôes clássicas que movem as pesquisas na área da sociologia da educação, com atenção para fatores individuais analisados à luz das variáveis e condição física dos alunos, cor, sexo, idade, num esforço analítico que busca tratar os efeitos combinados destas variáveis individuais, conjugando-as com o desempenho dos alunos, em linguagem e em matemática. Dados sobre a dimensão familiar, numa conjugação com o desempenho escolar, a partir de uma perspectiva da família como capital social, também sáo tratados com similar cuidado: descrição da família com atenção para variáveis importantes, como a presença dos pais em casa, diferenças de recursos sociais em famílias chefiadas por homens e mulheres, ocupaçáo materna, tempo disponível da mãe, ajuda recebida em casa, número de filhos na família. As expectativas familiares são também levadas em conta. A autora investe em questóes como a escolaridade desejada e a escolaridade esperada pelas mães; o desempenho médio, segundo a escolaridade esperada; e os fatores sociais das expectativas maternas. Assim como fez em relação aos fatores individuais, Barbosa irá também procurar analisar o efeito combinado das variáveis familiares, buscando compreender o capital social como fator de desempenho em linguagem e em matemática. Também trabalha a posição social das famílias, levando em consideração as variáveis como renda, escolaridade da mãe e trabalho infantil.

No capítulo 3, as professoras sáo as protagonistas, pois a autora irá examinar as características das professoras que podem ter influência sobre o desempenho dos estudantes. Dessa maneira, atenta para variáveis como treinamento profissional e trabalho, experiência, estilo e seus respectivos efeitos no desempenho dos alunos. Demonstra, assim, quanto é significativo o contexto da sala de aula como variável explicativa para a desigualdade do desempenho dos alunos. Eis um grande achado do livro, pois neste sentido a autora irá transpor as explicaçóes muito difundidas, que procuraram levar em consideração exclusivamente as variáveis individuais e sociofamiliares, de maneira quase naturalizada, como fatores das desigualdades de desempenho. Sem desmerecer tais variáveis bastante recorrentes, ao atentar para o trabalho docente e para o ambiente da sala de aula, a partir das práticas escolares, Maria Lígia demonstra como estes favorecem significativamente o incremento da igualdade de oportunidades.

No curto capítulo 4, a autora desenvolve alguns apontamentos sobre as escolas investigadas, num tratamento mais descritivo do que analítico, apontando um limite de sua pesquisa, ou seja, o fato de que em cada escola apenas uma sala de aula foi 
pesquisada. Assim, não se torna viável que se distingam possíveis efeitos da escola e de sua organizaçáo dos efeitos da sala de aula e do trabalho docente. Sáo, neste capítulo, apontados dados como as condiçóes físicas das escolas, as características humanas da organização escolar, com atenção para o papel da diretora e suas percepçóes sobre seu trabalho, o planejamento na escola e os programas em andamento nas escolas.

A discussão estabelecida no capítulo 5 focaliza a qualidade da escola e as desigualdades sociais. Sob esse aspecto, a autora procura demonstrar "que o efeito da escola pode, pelo menos em parte, reduzir os efeitos da posição social dos alunos sob o seu desempenho escolar" (p. 183, grifos da autora). Para tanto, trabalha com a definição de qualidade das escolas, centrando sua análise no desempenho em cada escola - levando em conta as médias em linguagem e matemática -, segundo a qualidade. $O$ resultado é comprovado com base nas diferenças de médias obtidas nos testes, favoráveis aos alunos de escolas avaliadas como de boa qualidade, independentemente da sua posiçáo econômica ou do capital cultural disponível na sua família. Dentre suas conclusóes, a autora verifica que seu trabalho possibilita "reforçar uma perspectiva que não é apenas analítica e que vê na escola um instrumento forte e eficaz de luta contra as desigualdades sociais".

Ainda que a autora aponte fatores individuais e sociais como barreiras ao desempenho escolar, penso que a grande contribuição de seu trabalho está no sentido de que sua percepção vai além dos determinismos sociais que muito já tomaram conta das análises sobre a educaçáo. Assim, demonstra um quadro otimista que aponta para a superação dos enfoques deterministas sobre o atual papel da educaçáo. A publicaçáo deste livro é bastante louvável, pela luz que lança sobre novas possibilidades de reflexáo acerca da relação entre desigualdade e desempenho escolar, como também por seus méritos enquanto um exemplar esforço de pesquisa empírica.

Márcio Ferreira de Souza Professor Adjunto do Departamento de Ciências Sociais da Universidade Federal de Uberlândia/MG marcfs@uol.com.br 